\title{
Perfil de riesgo de crédito para una coopertiva en Villavicencio a partir de un modelo logit
}

\section{Otto Smith Pardo Carrillo*}

Fecha de recibido: 24 de noviembre de 2018 Fecha de aprobado: 10 de abril de 2019

Para citar: Pardo Carrillo, O. S. (2020). Perfil de riesgo de crédito para una cooperativa en Villavicencio a partir de un modelo logit. Universidad \& Empresa, 22(38), 237.-256. https://doi.org/10.12804/revistas.urosario.edu.co/empresa/a.8266

Magíster en Economía, Universidad de Manizales. Economista, Universidad de los Llanos. Docente-Investigador, Universidad Santo Tomás, sede Villavicencio-Meta. Correo electrónico: ottopardo@santotomas.edu.co. ORCID 0000-00018759-0661 


\section{Resumen}

El perfilamiento de riesgo de crédito es un tema relevante para las entidades financieras, toda vez que identifica los factores generadores de riesgo de crédito (edad, género, capacidad de pago), además de contribuir en la implementación de Sistemas de Administración de Riesgo Crediticio (SARC). En ese sentido, este estudio estima el perfil de riesgos de los asociados (buenos y malos) de una cooperativa de ahorro y crédito en la ciudad de Villavicencio, que acceden a créditos en la modalidad de consumo, para lo cual se utiliza un modelo logit, que luego de ser aplicado arrojó como resultado que los asociados con esta cooperativa presentan como factores generadores de riesgo ser hombres, la corta edad, bajos ingresos, ser soltero, poca antigüedad como asociado, no tener personas a cargo, encontrarse empleado en empresas privadas, tener créditos con montos altos, al igual que su respectivo plazo.

Palabras clave: perfil de riesgo, riesgo de crédito, probabilidad de incumplimiento, modelo logit.

\section{Credit Risk Profile for a Cooperative in Villavicencio from a Logit Model T1 Abstract}

\section{Abstract}

Credit risk profiling is a relevant issue for financial institutions, since it identifies the factors that generate credit risk (age, gender, ability to pay), as well as contributing to the implementation of SARC Risk Management Systems. In this sense, this study estimates the risk profile of the associates (good and bad) of a savings and credit cooperative in the city of Villavicencio, who access credits in the consumption mode, using a logit model. After applying the model, the risk factors identified were being men, young age, low income, being single, low seniority as an associate, not having dependents, being employed in private companies, having credits with high amounts, as well as their respective terms.

Keywords: Risk profile, credit risk, probability of default, logit model.

\section{Perfil de risco de crédito para uma cooperativa em Villavicencio a partir de um modelo logit}

\section{Resumo}

O perfilhamento de risco de crédito é um tema relevante para as entidades financeiras, toda vez que identifica os fatores geradores de risco de crédito (idade, gênero, capacidade de pagamento), para além de contribuir na implementação de Sistemas de Administração de Risco SARC. Nesse sentido, este estudo estima o perfil de riscos dos associados *bons e maus) de uma cooperativa de poupança e crédito na cidade de Villavicencio, que acedem a créditos na modalidade de consumo, para o qual se utiliza um modelo logit, que depois de ser aplicado teve como resultado que os associados à mesma, apresentam como fatores geradores de risco, serem homens, a tenra idade, ingressos baixos, ser solteiro, pouca antiguidade como associado, não ter pessoas a cargo, ser empregado em empresas privadas, ter créditos com montantes altos, assim como seu respectivo prazo.

Palavras-chave: perfil de risco, risco de crédito, probabilidade de incumprimento, modelo logit. 


\section{Introducción}

A partir de los traumas causados por las crisis económicas como la del martes negro en 1929 en Nueva York, resulta sano mencionar que estas se han debido a un exceso de confianza en el sector financiero, de manera particular en lo que respecta a la colocación de créditos. De ahí que el Comité de Basilea, ${ }^{1}$ en reunión efectuada en 1975, identificara para la época el riesgo de crédito como la principal causa de dichas crisis financieras.

Bajo este contexto, el resultado del anterior ejercicio se denominó Acuerdo de Capitales Basilea I, cuyo propósito era mitigar el riesgo de crédito a partir de tres pilares: el primero consistente en hacer un provisionamiento de cartera del $8 \%$ del capital expuesto; el segundo relacionado con la creación de un ente regulador al interior de los países miembros del G-10, con el propósito de vigilar las entidades financieras, y el último que tiene que ver con la trasparencia que deben tener dichas entidades frente a las personas que deciden depositar sus ahorros.

Así mismo, la crisis financiera que se detonó en Estados Unidos en el año 2008, reafirmó la necesidad de seguir lo sugerido por Basilea I, lo que evidenció que las entidades financieras deben ser reguladas al interior de los países para mitigar el riesgo moral. En tal sentido, el estudio de riesgo de crédito se hace importante, y más en el caso particular de las Cooperativas financieras en la ciudad de Villavicencio, debido a que ellas están reguladas por la Superintendencia de Economía Solidaria.

Con respecto al SARC, es importante para las entidades financieras poder identificar el perfil de los buenos y malos asociados, ya que esto permite otorgar mejores créditos entendiendo que existe menor riesgos al aprobar solicitudes de crédito según su perfil; pero, para ello, es importante utilizar herramientas econométricas, como el modelo logit que permite clasificar clientes buenos y malos según sus características.

Para el caso particular de esta cooperativa, la utilización del modelo logit clasificó a los clientes malos con las siguientes características: los asociados con créditos de consumo, el

El Comité de Basilea es una entidad que genera los parámetros en materia de regulación financiera con el propósito de mantener la estabilidad económica a nivel mundial y está compuesto por; Bélgica, Francia, Canadá, Alemania, Japón, Italia, Suecia, Holanda, Reino Unido, Estados Unidos y Suiza. 
ser hombres, de poca edad, con menores ingresos, estar solteros, tener poca antigüedad como socio en la cooperativa, no tener personas a cargo, ser empleados de empresas privadas y tener créditos con montos altos, al igual de su respectivo plazo.

Este estudio se organiza en cinco secciones: la primera es el actual componente; la segunda se divide en dos partes: a) conocer el riesgo de crédito por medio de la historia y a luz de la literatura, lo que evidencia b) la importancia, principales modelos utilizados para estimación del riesgo de crédito y variables más significativas; seguido a esto, se hace una especificación metodológica que desagrega el paso a paso para la estimación del perfil de riesgos de la cooperativa financiera en Villavicencio, luego, se exponen los resultados del modelo, y finalmente, se hace una presentación de las conclusiones y recomendación del estudio.

\section{Revisión literaria}

El propósito de establecer la importancia de la modelación econométrica en la medición del riesgo de crédito es pertinente en el contexto financiero colombiano, debido a la necesidad de identificar los factores generadores de riesgo de crédito, además de medir la pérdida esperada e implementar controles. Por esta razón, en este trabajo se plantean dos componentes: el primero, tiene que ver con conocer el riesgo de crédito desde sus inicios hasta relacionarlo con sus definiciones a la luz de los referentes teóricos, y el segundo relacionado con evidenciar la utilización de los modelos estadísticos y econométricos que han sido empleados en la estimación de riesgos y sus variables más causales.

\subsection{El riesgo de crédito a la luz de la literatura}

La palabra riesgo de crédito nace a partir de la reunión celebrada por los gerentes de los bancos centrales de los diez países más poderos económicamente, el G-10, en 1975. El encuentro nace a partir de la preocupación por las consecuencias derivadas por las crisis financieras, y se le denominó Comité de Basilea. Para 1988, nace el primer acuerdo de capitales, el cual recibe como nombre Basilea I, documento en el cual se discutieron las causas de las crisis económicas mundiales, en el que se encontró que el causante principal de estas era el riesgo de contraparte, además de esto, se establecieron tres 
pailares para hacer frente a este fenómeno: el primero hace referencia al capital que deben provisionar las entidades financieras para solventar el incumplimiento al pago de la cartera por parte sus clientes; el segundo muestra la necesidad de contar con un ente regulador al interior de los países, que haga cumplir la normatividad en materia de riesgo de crédito, y el último tiene que ver con la transparencia que las instituciones financieras deben tener con sus clientes al momento de depositar sus ahorros.

\title{
Según Cardona (2004):
}

Se aspira que todos los bancos activos internacionalmente apliquen las nuevas recomendaciones consignadas en el acuerdo de capitales (Basilea I, 1988) y el nuevo acuerdo de capitales (Basilea II, 1999) que definen el capital mínimo que deben tener las entidades financieras para poder operar, relacionando el riesgo de los activos con el nivel y calidad del patrimonio, además, determina el capital mínimo necesario para que un banco haga frente a posibles quebrantos debido a los riesgos que maneja (p. 143).

En este mismo sentido, se observa la preocupación por parte del G-10 en establecer controles al riesgo de crédito, entendiendo que la mejor forma es castigar las utilidades de las entidades financieras con una provisión que correspondiente a sus niveles de riesgos. Al respecto Ochoa, Galeano y Agudelo (2010) afirman que:

\begin{abstract}
El objetivo de formular recomendaciones para la regulación de instituciones financieras y enfrentar de manera más eficaz las inestabilidades producidas por un mercado financiero mundial. Este organismo, consciente de que las instituciones se enfrentan al riesgo de crédito, hace público el Acuerdo de Capitales de Basilea en 1988, el cual es conocido como Basilea I, en dónde se hacen las recomendaciones necesarias, dada la importancia de asegurar la estabilidad del sistema y mantener un capital mínimo con el que se cubran los capitales sujetos al riesgo de posibilidad de impago, el cual se llamó capital mínimo regulatorio (p. 195).
\end{abstract}

Las crisis financieras se generan, en gran medida, por el nivel de riesgos que asumen las entidades financieras, estas se encuentran propensas al riesgo moral, debido a que los banqueros asumen un alto nivel de riesgos con el capital ajeno (captación de dinero). Además, Ochoa, Galeano y Agudelo (2010) sugieren que “[...] el riesgo moral ocurre 
cuando el prestamista, al ser captador de dinero por parte de los ahorradores, toma un gran riesgo debido a su alto rendimiento, situación a la que sería adverso si el dinero fuera suyo" (p. 194).

Así mismo, existe otra causa que influye en el no pago del cliente, y es la selección adversa, teoría desarrollada por Stiglitz (2000), en la cual existe un principal y un agente; para el caso del sector financiero, el principal sería el prestamista y el agente el prestatario. Los objetivos del prestamista y prestatario, tal como lo muestra la teoría, son diferentes y llegan a ser opuestos, mientras el primero busca obtener el capital prestado más la rentabilidad de este (intereses causados), el segundo tratará de devolver el capital recibido y la menor cantidad de intereses pactados. En relación con lo anterior, el prestatario no revelará sus información al cien por ciento, sino que tratará de ocultarla en pro de obtener un mayor monto de crédito aprobado por el prestamista.

En tal sentido, al no existir un flujo de información completa y veraz de parte del prestatario hacia el prestamista, surge un fenómeno llamado la selección adversa, la cual desde los planteamientos de Ochoa, Galeano y Agudelo (2010):

Surge cuando la falta de información hace que el ente prestador no conozca de manera perfecta el tipo de agente al cual le pretende otorgar un crédito, no tiene la información suficiente para determinar si el individuo tiene la capacidad adquisitiva que informa tener o si logrará cumplir sus obligaciones (p. 194).

Con base en lo anterior, el incumplimiento no solo se origina por la selección adversa, también existen fenómenos macroeconómicos que afectan la capacidad de pago de las personas. En este orden de ideas, el ciclo económico impacta directamente a los ingresos de las personas; en momentos de crisis, las empresas disminuyen su producción, y esto a su vez esta concatenado con el recorte de personal, lo que conlleva a que las personas que se endeudaron por expectativas de ingresos futuros tiendan a no cumplir con lo establecido en los contratos de créditos aceptados (Hernández, Meneses \& Benavides, 2005).

A raíz de lo anterior, el riesgo de crédito, visto desde los diferentes enfoques, es el principal causante de las crisis financieras, las cuales afectaron económica y socialmente 
a los países que la padecieron, para validar lo anterior Caicedo, Claramunt y Casanovas (2011) reafirman que:

La crisis financiera que se reveló en el año 2007, y que se profundizó en los años 2008 y 2009, ratifica una vez más, y ha dejado de manifiesto, que la gestión del riesgo de crédito, específicamente su medición, es un tema de vital importancia para reguladores, directores de empresas e inversionistas, por los efectos sistemáticos que dicho riesgo puede ocasionar (p. 75).

Por lo anterior, es importante que las empresas dedicadas al negocio financiero implementen un Sistema de Administración de Riesgo de Crédito (SARC), que permita un reconocimiento oportuno de los factores de riesgos y su respectivo impacto en relación con la pérdida esperada. En ese sentido, Pérez y Fernández (2007) afirman que: "debe existir un sistema de administración del riesgo como un procedimiento para identificarlos, medirlos y tomar las medidas preventivas que permitan enfrentarlos de la mejor manera posible" (p. 78).

Por otra parte, es importante hacer un seguimiento a las diferentes definiciones de riesgo crédito. Desde Basilea i se conceptualizó el riesgo de contraparte como la probabilidad de no pago de un crédito bajo las condiciones establecidas, llevando a las entidades financieras a pérdidas. Bajo esta línea, Cardona (2004) define al riesgo de crédito como "la posibilidad de que una entidad incurra en pérdidas y se disminuya el valor de sus activos como consecuencia de que sus deudores fallen en el cumplimiento oportuno o cumplan imperfectamente los términos contractuales acordados” (p. 142).

Así mismo, Vélez (2009) afirma que "el riesgo de crédito surge cuando las contrapartes están dispuestas o son totalmente incapaces de cumplir sus obligaciones contractuales" (p. 37). La definición de riesgo de crédito por este referente teórico sigue la misma línea del anterior, en donde el riesgo de contraparte se origina cuando los deudores empiezan a incumplir con los pagos establecidos, ya sea por voluntad de sí mismo o por falta de capacidad de pago, incumpliendo así el contrato de crédito, situación que lleva a responsabilizar a los prestatarios, más no a la flexibilización del prestamista a la hora de otorgar el crédito. 
En igual sentido, Caicedo, Claramunt y Casanovas (2011), afirman que. "El riesgo de crédito se define como la pérdida potencial que se registra con motivo del incumplimiento de una contraparte en una transacción financiera" (p. 75). Adicional a esto, estos mismos autores reconocen la importancia de la garantía como seguro de pago, en caso de que la capacidad de pago del cliente se desmejore o se presente un deterioro en el valor de la garantía, en cuyo caso, el riesgo de contraparte tiende a incrementar.

Apoyan esta perspectiva Támara, Aristizábal y Velásquez (2012) al afirmar que "la probabilidad de incumplimiento de un cliente está dada cuando este alcance una altura de mora n" (p. 109). Es decir, que cliente presente un retraso en el pago de las cuotas pactadas, ya que en el incumplimiento existen otros aspectos como la restructuración de los créditos en materia del valor de la cuota, renegociación del plazo, de la tasa de interés y de la fecha de pago, entre otros.

Por tal razón, Medina y Paniagua (2007) plantean que "los efectos de la posible insolvencia de sus clientes justifican la necesidad de desarrollar herramientas de evaluación de la capacidad para afrontar sus deudas" (p. 216). La anterior definición establece que el riesgo de crédito es la incapacidad de pago de los clientes para cumplir a cabalidad con sus obligaciones financieras, la solución a dicho problema estaría en la creación de herramientas estadísticas o econométricas para la estimación de la probabilidad de incumplimiento.

De otra parte, Fernández y Pérez (2005) declaran que "el riesgo puede ser definido como la volatilidad de los flujos financieros no esperados, generalmente derivada del valor de los activos o los pasivos" (p. 58). Lo que sugiere implementar un enfoque de estabilidad para la empresa, examinando la volatilidad o la varianza del precio de los activos de la empresa, para que en un futuro no se comprometa la capacidad de pago de esta y se garantice el cumplimiento de sus obligaciones financieras.

\subsection{La importancia de la modelación en la medición del riesgo de crédito}

El SARC está compuesto por cuatro etapas: 1) identificación de los factores de riesgo de crédito que afectan el pago de las cuotas por parte de los clientes, 2) la medición del 
impacto económico que se asume cuando están implícitos estos factores y no se controlan, 3) el control de dichos factores y 4) el seguimiento del control establecido sobre el factor identificado.

De ahí que la medición del riesgo cuando se implementa el sARC se enfoque en las dos primeras etapas. Razón por la cual Cardona (2004) establece que:

La importancia de tener un modelo de cálculo de probabilidad de incumplimiento confiable y con una alta capacidad de discriminación radica en que esta impacta considerablemente el cálculo de provisiones, afectando directamente el balance y las utilidades que podría llegar a tener la entidad" (p. 150).

Lo anterior permite dar un buen uso al capital, ya que si se provisiona demasiado en comparación a los niveles de riesgos tolerados, se deja capital ocioso, o, si se provisiona poco, provoca un problema de iliquidez; por tanto, al momento de cubrir monetariamente la materialización de los eventos y que estos no alcancen, se utiliza "el modelo de regresión logística que modela la toma de decisiones cuando se está enfrente de un proceso de elección binaria, y el proceso de decisión de la probabilidad asociada a cada alternativa posible que puede tener un cliente" (Fernández \& Pérez, 2005, p. 6).

Así como los modelos logit permiten hallar la probabilidad de incumplimiento y la tasa de pérdida para estimar la pérdida esperada, los modelos probabilísticos de elección binaría segmentan los clientes, entre buenos pagadores y malos pagadores, incluso se han empleado para elaboración de scoring, los cuales, según Trejo, Martínez y Venegas (2017):

Posibilitan una reducción significativa en los tiempos de ejecución de los distintos procesos financieros para el otorgamiento y seguimiento de un crédito, permitiendo con ello una mayor automatización y reduciendo la necesidad de la intervención humana en la evaluación y estimación del riesgo crediticio (p. 380).

Sin duda, los modelos econométricos son útiles en la medida en que posibilitan tomar decisiones de acuerdo con estimaciones probabilísticas, excluyendo la subjetividad, la cual está más intrínsecamente relacionada con la intervención humana en el proceso de colocación. 
Ahora bien, lo largo de la literatura se evidencia la utilización de varios métodos estadísticos y econométricos que son empleados para identificar los riesgos de créditos, entre los más utilizados se encuentran los modelos logit o logísticos, porque permiten establecer la probabilidad del no pago, dadas determinadas características (Fernández \& Pérez, 2005; Salazar, 2013; Vélez, 2009; Espin \& Rodríguez, 2013 y Trejo, Martínez \& Venegas, 2017). También se emplean modelos probit, tal como lo evidencian Alfaro, Calvo y Oda (2008).

Si bien es cierto que uno de los metodos más empleados por su nivel de utilidad son las redes neuronales, en donde se entrenan algoritmos que, apartir de dicho aprendizaje, le permite a la red tomar sus propias decisiones como un cerebro, tal como lo presenta Pérez y Fernández (2007), su falencia radica en que la red neuronal es como una caja negra: encuentra los factores de riesgos pero no los muestra, sólo lo sabe la red. Así mismo, aunque las variables más empleadas para establecer el perfil de riesgos de los clientes de una entidad pueden variar según la región, para Salazar (2013), las variables más significativas son plazo, género, nivel de educación, capacidad de endeudamiento, sector productivo al que pertenece, entre otros.

Por otro lado, Ochoa, Galeano y Agudelo (2010) emplean el monto, garantía, créditos reestructurados, edad, ocupación, nivel educativo, ingreso, estrato social, antigüedad laboral, estado civil, plazo y género, entre otras; mientras que Fernández y Pérez (2005) utilizan las variables antigüedad laboral, antigüedad como socio, estrato socioeconómico, ingresos, nivel de escolaridad. En este mismo sentido, Espin y Rodríguez (2013) utilizan género, estado civil, educación, tipo de vivienda, profesión, ingresos, edad, capacidad de pago declarada, número de personas que dependen económicamente, tiempo en el actual empleo, entre otras, como variables.

\section{Metodología}

El modelo logit es originario de la familia de los modelos de respuesta cualitativa, en donde la variable a explicar es de tipo binario, toma el valor de 1 cuando el objeto de estudio pertenece a una condición específica o 0 si es lo contrario. Para este estudio en particular toma el valor de 1 si el cliente es incumplido y 0 si es cumplido, en este 
sentido, para entender este modelo, se parte de la explicación de un modelo lineal probabilístico (MLP), tal como lo expresa la ecuación 1.

$$
P_{i}=\beta_{1}+\beta_{2} X_{i}
$$

El MLP establece la probabilidad de ocurrencia de un evento. Cuando existe una variable explicativa $X_{i}$, la relación de dicha variable con $P_{i}$ es lineal, sobrepasando la probabilidad del $100 \%$ a medida que incrementa la relación, mientras que la variable explicativa en el modelo logit se mantiene entre un rango de 0 a 1, tal como lo muestra la ecuación 2 .

$$
P_{i}=\frac{1}{1+e^{-\left(\beta_{1}+\beta_{2} X_{2}+\ldots+\beta_{k} X_{k}+U_{i}\right)}}
$$

Para una mejor interpretación, se reescribe la ecuación 2 de la siguiente forma.

$$
P_{i}=\frac{1}{1+e^{-Z_{i}}}=\frac{e^{Z}}{1+e^{Z}}
$$

La ecuación 3 muestra la representación de una función de distribución logística, $Z_{i}$ está entre un rango de $-\infty$ a $+\infty$, mientras que $P_{i}$ se encuentra entre 0 a 1 y $P_{i}$ no está linealmente relacionado con $Z_{i}$ por lo cual cumple con la condición.

$$
1-P_{i}=\frac{1}{1+e^{Z_{i}}}
$$

Si $P_{i}$ es la probabilidad de que ocurra el evento, la ecuación 4 evidencia la probabilidad de que no ocurra el evento.

$$
\frac{P_{i}}{1-P_{i}}=\frac{1++e^{Z_{i}}}{1+e^{-Z_{i}}}=e^{Z_{i}}
$$

De tal forma que la ecuación 5 presenta la razón de las probabilidades, mostrando la probabilidad de que ocurra un evento frente a que no ocurra.

$$
L_{i}=\operatorname{In} \frac{P_{i}}{1-P_{i}}=Z_{i}=\beta_{1}+\beta_{2} X_{i}+u_{i}
$$

$L_{i}$, es el logaritmo natural de la razón de probabilidades o logit, de esta forma $X_{i}$ y los parámetros son lineales con respecto a $L_{i}$, además si $X ß$ tiende a $\infty$, entonces $e^{-X \beta}$ tiende a 
0 y $1 / 1+e^{-X \beta}$ tiende a 1 , pero $X ß$ tiende a $-\infty$, entonces $e^{-X \beta}$ tiende a $\infty$ y $1 / 1+e^{-X \beta}$ tiende a 0 , por lo tanto, $L_{i}$ es una variable discreta que solo puede tomar valores entre 1 y 0 . Donde 1 representa a los asociados que han tenido un mal desempeño en su cartera, alcanzando el punto default y 0 los que han tenido un buen comportamiento. Bajo las siguientes condiciones se propone el siguiente modelo.

$$
\begin{aligned}
& Y_{i}=\beta_{1}+\beta_{2} \text { Ed }_{i}+\beta_{3} \text { Ing }_{i}+\beta_{4} \text { Plaz }_{i}+\beta_{5} \text { Gene }_{i}+\beta_{6} \text { Ant }_{i}+\beta_{7} \text { Mon }_{i}+\beta_{8} \text { Esp }_{i}+\beta_{9} \text { EsO }_{i} \\
& +\beta_{10} \text { Estc }_{i}+\beta_{11} \text { Per }_{i}+u_{i}
\end{aligned}
$$

Donde, el subíndice $i$ representa a cada asociado con un crédito de consumo, $Y_{i}$ es incumplimiento, esta variable toma el valor de 1 cuando no cumple con las condiciones establecidas al momento de aceptar el crédito, y 0 cuando cumple $E d_{i}$ es la variable edad, es numérica y está medida en años; $I_{n} g_{i}$ es la variable logaritmo natural del ingreso total, está dada en términos porcentuales; Plaz $_{i}$ es la variable plazo, es numérica y está en meses; es la variable género, es dicótoma, toma el valor de 11 cuando es mujer y 0 cuando es hombre; $\boldsymbol{A n t} t_{i}$ es la variable antigüedad como socio, es numérica y está en meses; Mon $_{i}$ es la variable logaritmo natural del monto prestado, es numérica y está dada en términos porcentuales; $E s p_{i}$ es la variable empleado del sector privado, es dicótoma y toma el valor de 11 cuando el individuo pertenece a este sector y 0 cuando no; Eso ${ }_{i}$ es la variable empleado del sector oficial, es dicótoma y toma el valor de 1 cuando el individuo pertenece a este sector y 0 cuando no; Estc $_{i}$ es la variable estado civil, es dicótoma, toma el valor de uno cuando es soltero y cero cuando es casado y Per es la variable personas a cargo, es numérica y va desde 0 a 4 .

La Circular Externa 027 de 2011 de la Superintendencia Financiera de Colombia (SFC), establece que el incumplimiento se da cuando se den cualquiera de los siguientes criterios: créditos de consumo que se encuentren en mora más de 90 días, cuando el asociado registre obligaciones castigadas con la entidad o cualquier otra institución financiera, cuando el asociado presente obligaciones reestructuradas con la entidad o cualquier otra institución financiera, cuando el asociado se encuentre en proceso judicial a raíz del no pago de la obligación financiera, lo anterior, sin perjuicio de que la entidad establezca criterios más exigentes.

En ese orden de ideas, para este estudio se plantea mínimo el 50\% de deterioro de la cartera de consumo, mediante la metodología propuesta por Markov (Matrices de Transición), 
esta metodología permite ver la $P_{i j}$ (la probabilidad de que un crédito estando en una categoría $i$ migre a otra $j$ ) en un periodo determinado (doce meses). Para lograr aplicar esta metodología es importante tener en cuenta los siguientes supuestos: primero que todos los $P_{i j}$ son positivos, segundo que la suma de cada fila siempre dé como resultado 1 . En ese orden de ideas, se plantea la siguiente ecuación.

$$
P_{i j}=\frac{N_{i j}}{N_{i}} \text { para todo } i \mathrm{y} j .
$$

Dónde,

$N_{i}$, es la cantidad de créditos que empezaron en $i$.

$N_{i j}$, es la cantidad de créditos que estaban en $i$ quedaron en $j$.

Para mejor estimación de las matrices de transición, es necesario aplicar la siguiente formula.

$$
P_{i j} \text { Promedio }=\sum_{t=0}^{T} Z_{t} P_{i j}(t)
$$

Dónde,

$Z_{t}$, es la participación o ponderación para cada momento de tiempo estudiado.

Al aplicar la metodología de Markov, se encontró, según la tabla 1, que los créditos que empezaron en la categoría B tienden a migrar a otras categorías, el deterioro de cartera para esta calificación es del 57.33\%, sobrepasando la condicional inicialmente propuesta, en la cual el límite es del $50 \%$, en relación a lo anterior, el incumplimiento se da cuando un asociado está en calificación B o cualquier otra que esté por encima de esta (C, D o E). En relación con la base de datos proporcionada por la cooperativa, hay 4019 asociados que han tenido o tienen créditos de consumo, de los cuales 2042 asociados están categorizados como incumplidos y 1977 como cumplidos. 
Tabla 1. Deterioro de la cartera de consumo

\begin{tabular}{ccccccc}
\hline & A & B & C & D & E & Deterioro \\
\hline A & $92.84 \%$ & $2.37 \%$ & $1.13 \%$ & $1.74 \%$ & $1.92 \%$ & $\mathbf{7 . 1 6 \%}$ \\
\hline B & $33.24 \%$ & $9.42 \%$ & $6.85 \%$ & $13.10 \%$ & $37.38 \%$ & $\mathbf{5 7 . 3 3 \%}$ \\
\hline C & $21.68 \%$ & $6.22 \%$ & $4.94 \%$ & $11.76 \%$ & $55.40 \%$ & $\mathbf{6 7 . 1 6 \%}$ \\
\hline D & $8.95 \%$ & $2.14 \%$ & $2.60 \%$ & $9.86 \%$ & $78.93 \%$ & $\mathbf{7 8 . 9 3 \%}$ \\
\hline E & $3.51 \%$ & $0.82 \%$ & $1.16 \%$ & $3.21 \%$ & $91.30 \%$ & \\
\hline
\end{tabular}

Fuente: elaboración propia a partir de los datos brindados por la Cooperativa.

\section{Resultados}

El modelo tiene una serie de supuestos que deben ser validados, el primero es la ausencia de heterocedasticidad o la diferencia de la distribución de los errores. En el caso de los modelos logit, a medida que la población tiende a ser más grande, la distribución de los errores pasan de una binomial a una normal, de tal forma que este tipo de modelos son propensos a presentar problemas de heterocedasticidad, en este sentido, se aplicaron errores estándar robustos para eliminar el problema.

Así mismo, otro supuesto importante es la no presencia de multicolinealidad, en este caso particular se realizó una prueba de correlación entre las variables del modelo. Los resultados permitieron ver el impacto de las con, mostrando que las variables seleccionadas influyen de manera importante en la variable significativa, además, esta herramienta permite validar que no existe correlación entre las variables explicativas, según la tabla 2, los valores de correlación están por debajo de 55\%, por esta razón no existe multicolinealidad.

Tabla 2. No presencia de multicolinealidad en las variables del modelo

\begin{tabular}{|c|c|c|c|c|c|c|c|c|c|c|c|}
\hline & $Y$ & Ed & Ing & Plaz & Gene & Ant & Mon & Esp & Eso & Estc & Per \\
\hline$Y$ & $100 \%$ & & & & & & & & & & \\
\hline $\mathrm{Ed}$ & $-22 \%$ & $100 \%$ & & & & & & & & & \\
\hline Ing & $-13 \%$ & $23 \%$ & $100 \%$ & & & & & & & & \\
\hline Plaz & $14 \%$ & $-1 \%$ & $26 \%$ & $100 \%$ & & & & & & & \\
\hline Gene & $-4 \%$ & $-10 \%$ & $-11 \%$ & $2 \%$ & $100 \%$ & & & & & & \\
\hline Ant & $-26 \%$ & $39 \%$ & $19 \%$ & $-3 \%$ & $-6 \%$ & $100 \%$ & & & & & \\
\hline
\end{tabular}




\begin{tabular}{cccccccccccc}
\hline & Y & Ed & Ing & Plaz & Gene & Ant & Mon & Esp & Eso & Estc & Per \\
\hline Mon & $23 \%$ & $-17 \%$ & $-0.8 \%$ & $53 \%$ & $10 \%$ & $-33 \%$ & $100 \%$ & & & & \\
\hline Esp & $15 \%$ & $-31 \%$ & $-29 \%$ & $-0.4 \%$ & $-7 \%$ & $-12 \%$ & $-4 \%$ & $100 \%$ & & & \\
\hline Eso & $-15 \%$ & $17 \%$ & $14 \%$ & $-0.7 \%$ & $10 \%$ & $19 \%$ & $-11 \%$ & $-26 \%$ & $100 \%$ & & \\
\hline Estc & $0.7 \%$ & $6 \%$ & $2 \%$ & $0.8 \%$ & $10 \%$ & $4 \%$ & $-0.8 \%$ & $3 \%$ & $4 \%$ & $100 \%$ & \\
\hline Per & $0.8 \%$ & $-6 \%$ & $3 \%$ & $6 \%$ & $-8 \%$ & $-11 \%$ & $10 \%$ & $3 \%$ & $-6 \%$ & $-2 \%$ & $100 \%$ \\
\hline
\end{tabular}

Fuente: elaboración propia a partir de los datos brindados por la Cooperativa

Después de validar los supuestos del modelo, se procedió a analizar la bondad de ajuste; en este caso, utilizando el count, que representa el nivel de predictibilidad del modelo o en qué porcentaje las variables exógenas explican a la endógena, según la tabla 3, este es de un $68.11 \%$, mientras que la capacidad del modelo para acertar cuáles son malos clientes es de $69.34 \%$, así mismo, el nivel de aciertos de buenos es de un $63.95 \%$, lo anterior sin duda permite decir que el modelo tiene un nivel de clasificación aceptable para predecir el perfil de riesgo de los asociados con créditos de consumo de la cooperativa de la ciudad de Villavicencio.

Los resultados del modelo presentados en la tabla 3 permiten afirmar que los asociados que tienen créditos de consumo en la cooperativa de la ciudad de Villavicencio presentan, algunas características asociadas con el perfil de riesgos, por ejemplo, con respecto a la edad, por cada año que tenga de vida el asociado, la probabilidad de incumplimiento disminuye en un $0.45 \%$, esto ocurre porque las personas más adultas tienden a ser más responsables ante las obligaciones adquiridas, además, de la relación con la variable ingresos: a mayor edad mayor nivel de ingresos.

Así mismo, por cada $1 \%$ de incremento en el ingreso de los asociados que tienen créditos de consumo, la probabilidad de incumplir disminuye en un 6.74\%. Las personas que se encuentran asociadas con la cooperativa tienden a ser mejores pagadores en la medida que devengan mejores salarios, demostrando honestidad, al no caer en la voluntad no de pagar.

Por otro lado, por cada mes que tenga de más el crédito, la probabilidad de incumplimiento incrementa en $0.33 \%$, lo que demuestra que es menos riesgoso otorgar créditos con menores plazos, lo anterior debido a la falta de experiencia crediticia que poseen algunos asociados. Para el caso particular del sector cooperativo está la costumbre de prestar mayores montos a plazos más extensos a los asociados con aportes cuantiosos 
y con mayor antigüedad como socio de esta, dejando de lado la historia crediticia como variable a analizar en el proceso de colocación.

Así mismo, la probabilidad de incumplimientos disminuye en un $8.44 \%$ si el asociado es mujer, lo cual confirma la buena disposición de ese género al momento de pagar, pensando en la posibilidad de acceder a nuevos créditos en el futuro que les puedan ser útiles.

De otra parte, se ve en los asociados más antiguos que, por cada mes de antigüedad en la cooperativa, la probabilidad de impago disminuye en un $0.11 \%$, debido al compromiso que tienen con la cooperativa y los beneficios a los que pueden acceder como socios, es la confianza que quieren generar para poder estar en posiciones más privilegiadas al interior de la entidad.

Tabla 3. Resultados del modelo logit

\begin{tabular}{|c|c|}
\hline Variable & Efectos Marginales \\
\hline Ed & $\begin{array}{c}-0.0045583^{\star \star \star} \\
(0.00105)\end{array}$ \\
\hline Ing & $\begin{array}{c}-0.0674542^{\star \star \star} \\
(0.01751)\end{array}$ \\
\hline Plaz & $\begin{array}{c}0.0033498^{\star \star \star} \\
(0.00102)\end{array}$ \\
\hline Gene & $\begin{array}{c}-0.084416^{\star \star \star} \\
(0.02148)\end{array}$ \\
\hline Ant & $\begin{array}{c}-0.0011029^{* \star \star} \\
(0.00016)\end{array}$ \\
\hline Mon & $\begin{array}{c}0.0341458^{\star \star \star} \\
(0.00016)\end{array}$ \\
\hline Esp & $\begin{array}{c}0.0803964^{*} \\
(0.04814)\end{array}$ \\
\hline Eso & $\begin{array}{c}-0.0995093^{\star \star} \\
(0.04707)\end{array}$ \\
\hline Estc & $\begin{array}{c}0.1512426^{*} \\
(0.08706)\end{array}$ \\
\hline Per & $\begin{array}{c}-0.0395331^{\star \star} \\
(0.01796)\end{array}$ \\
\hline Count R2 & 0.666 \\
\hline Sensitivity & $69.34 \%$ \\
\hline Specificity & $63.95 \%$ \\
\hline Correctly classified & $66.57 \%$ \\
\hline
\end{tabular}

Nota: Error estándar en paréntesis $y{ }^{\star \star *} p<0.01,{ }^{* \star} p<0.05,{ }^{*} p<0.1$

Fuente: elaboración propia a partir de los datos brindados por la Cooperativa. 
Por otro lado, la tabla 3 muestra que si el valor del monto incrementa en un $1 \%$, la probabilidad de incumplimiento aumenta en un $3.41 \%$, lo cual hace que esta variable sea riesgosa en la medida en que se aprueben montos excesivos. Esto ocurre en especial en las cooperativas, dado que el tamaño del monto depende de la cantidad de aportes que posea el asociado en el momento de solicitar el crédito, restándole importancia a variables como la capacidad de pago y experiencia crediticia.

De igual forma, las asociados que son empleados de empresas privadas, en comparación con los pensionados, tienen una probabilidad de incumplir del $8.03 \%$ porque los ingresos de dichas personas tienden a ser más volátiles, debido a la misma dinámica de dichas empresas. Caso diferente se observa con los asociados que son empleados del sector oficial, estos presentan una disminución del $9.95 \%$ en la probabilidad de incumplimiento.

De otro lado, la probabilidad de incumplimiento incrementa en $15.12 \%$ si el asociado es soltero, porque tiende a tener menor responsabilidades de tipo financiero, lo que permite asumir un mayor nivel de riesgo a la hora de decidir no pagar por razones de capacidad de pago o por voluntad.

Cabe señalar que por cada persona a cargo, la probabilidad de incumpliendo disminuye en $3.95 \%$, debido a que esta variable está relacionada con el estado civil. La mayoría de los que tienen personas a cargo están casados, tal como lo muestra la tabla 4, además, esto confirma que las personas casadas son más responsables, al ser más renuentes al riesgo, tomando cautela a la hora de solicitar financiamiento porque entienden que en el futuro pueden necesitar de las entidades financieras a la hora de ejecutar un proyecto.

Tabla 4. Relación estado civil vs personas a cargo

\begin{tabular}{cccc}
\hline Personas a cargo & Casado & Soltero & Total \\
\hline 0 & 2350 & 30 & 2380 \\
\hline 1 & 131 & 3 & 134 \\
\hline 2 & 87 & 0 & 87 \\
\hline 3 & 40 & 0 & 40 \\
\hline 4 & 6 & 0 & 6 \\
\hline
\end{tabular}

Fuente: elaboración propia a partir de los datos brindados por la Cooperativa. 


\section{Conclusiones}

En relación con lo tratado en esta investigación, se puede validar de manera teórica la importancia de gestionar el riesgo de crédito en las entidades financieras mediante la utilización de herramientas cuantitativas, como modelos econométricos de elección binaria, en especial el modelo logit, ya que permite generar un resultado con ausencia de subjetividades a la hora de analizar las solicitudes de crédito, y más para el caso de las cooperativas de ahorro y crédito de la ciudad de Villavicencio, en donde la mano de obra especializada en conocimientos de estadística es escasa y la poca que hay no se somete a los salarios ofrecidos para dichos cargos.

Por otro lado, los resultados del modelo logit permiten establecer el perfil de riesgos de la cooperativa, el cual obedece a las siguientes características de los asociados con créditos de consumo: ser hombres, de poca edad, con menores ingresos, estar solteros, tener poca antigüedad como socios en la cooperativa, no tener personas a cargo, ser empleados de empresas privadas y tener créditos con montos altos, al igual de su respectivo plazo. Así mismo, es importante que la cooperativa preste atención a la variable monto porque es bastante riesgosa, toda vez que ellos se basan en la cantidad de aportes del asociado para determinar el valor a prestar, obviando la capacidad de pago como principal variable a estudiar para validar dicho desembolso.

En relación con lo anterior, es importante que la cooperativa realice los respectivos controles de los factores de riesgo identificados. Así mismo, esta entidad debe realizar campañas comerciales con base en el perfil de los buenos asociados, en materia de probabilidad de pago, esto con el fin de colocar créditos más seguros que les permitan maximizar sus beneficios.

Con base en los resultados, se sugiere realizar investigaciones en relación con la consolidación de scoring para otras cooperativas de la ciudad de Villavicencio. También es importante incursionar en otras líneas, como la comercial y microcrédito, en especial esta última, ya que la forma de otorgar créditos se basa en cálculos contables, no el estudio de las características de los clientes que quieren acceder a ese tipo financiamiento. 


\section{Referencias}

Alfaro, R., Calvo, D. \& Oda, D. (2008). Riesgo de crédito de la banca. Banco Central de Chile. Documentos de Trabajo, 503, 1-29. Recuperado de https://dialnet.unirioja.es/descarga/ articulo/2870772.pdf

Caicedo, E., Claramunt, M. \& Casanovas, M. (2011). Medición del riesgo de crédito mediante modelos estructurales: Una aplicación al mercado colombiano. Cuadernos de administración, 24(42), 73-100. Recuperado de http://www.scielo.org.co/pdf/cadm/v24n42/ v24n42a04.pdf

Cardona, P. (2004). Aplicación de árboles de decisión en modelos de riesgo crediticio. Revista Colombiana de Estadística, 27(2), 139-151. Recuperado de https://revistas.unal.edu.co/ index.php/estad/article/view/28808

Espin, O. \& Rodríguez, C. (2013). Metodología para un scoring de clientes sin referencias crediticias. Cuadernos de economía, 32(59), 137-161. Recuperado de https://revistas.unal. edu.co/index.php/ceconomia/article/.../40677

Fernández, H. \& Pérez, F. (2005). El modelo logístico: Una herramienta estadística para evaluar el riesgo de crédito. Revista Ingenierías Universidad de Medellín, 4(6), 55-75. Recuperado de www.redalyc.org/articulo.oa?id=75040605

Hernández, L., Meneses, L. \& Benavides, J. (2005). Desarrollo de una metodología propia para el análisis de crédito empresarial en una entidad financiera. Estudios gerenciales, 97, 129-165. Recuperado de www.scielo.org.co/pdf/eg/v21n97/v21n97a07.pdf

Medina, S. \& Paniagua, G. (2007). Modelo de inferencia difuso para estudio de crédito. Dyna, 154, 215-229. Recuperado de http://www.scielo.org.co/pdf/dyna/v75n154/a20v75n154.pdf

Ochoa, J., Galeano, W. \& Agudelo, L. (2010). Construcción de un modelo de scoring para el otorgamiento de crédito en una entidad financiera. Perfil de Coyuntura Económica, 16, 191-222. Recuperado de http://www.scielo.org.co/pdf/pece/n16/n16a10.pdf

Pérez, F. \& Fernández, H. (2007). Las redes neuronales y la evaluación del riesgo de crédito. Revista Ingenierias Universidad de Medellín, 6(10), 77-91. Recuperado de http://www. scielo.org.co/pdf/rium/v6n10/v6n10a07.pdf

Salazar, F. (2013). Cuantificación del riesgo de incumplimiento en créditos de libre inversión: un ejercicio econométrico para una entidad bancaria del municipio de Popayán, Colombia. Estudios Gerenciales, 29(129), 416-427. Recuperado de https://www.icesi.edu.co/revistas/ index.php/estudios.../1737

Stiglizt, J. (2002). La información y el cambio en el paradigma en la ciencia económica. Revista Asturias de Economía (RAE), (25). Recuperado de file://C:/Users/Usuario/Downloads/ Dialnet- LaInformacionYElCambioEnElParadigmaDeLaCienciaEcon-2305220.pdf 
Támara, A., Aristizábal, R. \& Velásquez, E. (2012). Matrices de transición en el análisis del riesgo de crediticio como elemento fundamental en el cálculo de la pérdida esperada en una institución financiera colombiana. Revista Ingenierías Universidad de Medellín, 11(20), 105-114. Recuperado de http://www.scielo.org.co/pdf/rium/v11n20/v11n20a09.pdf

Trejo, J., Martínez, M. \& Venegas, F. (2017). Administración del riesgo crediticio al menudeo en México: una mejora econométrica en la selección de variables y cambios en sus características. Contaduría y Administración, 62(2), 377-398. Recuperado de http://www.cya. unam.mx/index.php/cya/article/view/835/864

Vélez, C. (2009). Modelo de riesgo crediticio para la empresa funeraria. Revista Ciencias Estratégicas, 17(21), 33-47. Recuperado de https://revistas.upb.edu.co/index.php/cienciasestrategicas/.../575 